\title{
Effects of drying and/or quenching histories on lateral tensile deformation properties of water-swollen wood
}

\author{
Yuka Miyoshi $^{1} \cdot$ Tomoaki Kiryu $^{1} \cdot$ Keisuke Kojiro $^{2} \cdot$ Yuzo Furuta $^{1}$
}

Received: 3 April 2015/Accepted: 18 June 2015/Published online: 2 August 2015

(C) The Japan Wood Research Society 2015

\begin{abstract}
Lateral tensile deformation properties of wood were studied to clarify the tensile deformation properties of wood with drying and/or quenching histories, and it was discussed whether giving these histories was effective to increase the lateral tensile deformation of wood. The results obtained are as follows. In all of the samples with drying and/or quenching histories, failure strain was increased and elastic modulus was decreased. In all of the measurement conditions, the failure strain of $45^{\circ}$ angle sample with history was the largest. This result was caused by the shearing deformation of cells which showed diamond-shaped deformation during increasing tensile stress. This shearing deformation of the cell shape was promoted by increase of fluidity and decrease of elastic modulus which were caused by treatment of drying and/or quenching. These results suggest that giving drying and/or quenching histories is effective for wood to increase the tensile deformation even in water saturated condition at $25{ }^{\circ} \mathrm{C}$.
\end{abstract}

Keywords Lateral tensile deformation property · Drying history · Quenching history · Different tensile direction

\section{Introduction}

Techniques for deforming wood into various shapes are required to improve the processability of wood products. However, wood has a low ductility. When veneers are

Yuka Miyoshi

miyo118mint@yahoo.co.jp

1 Division of Environmental Sciences, Graduate School of Life and Environmental Sciences, Kyoto Prefectural University, Hangi-cho, Shimogamo, Sakyo-ku, Kyoto 606-8522, Japan

2 WithGarden Co., Ltd., Suginami-ku, Tokyo 168-0072, Japan press molded into a tray or pasted on the curved surface, cracks often occur in large parts of the curvature. It is considered that the reasons for these problems are due to small lateral tensile deformation and strength. Therefore, to improve the processability of wood, first of all, it is necessary to understand the characteristics of the lateral tensile deformation of wood. And then, these studies should be applied to the various deformation processes technology of wood. However, physical properties of lateral tensile deformation have not been made sufficiently clear in previous studies. So, in our previous report, we have studied lateral tensile deformation properties at various moisture content, temperatures, angle to annual rings, and species in the same size of samples [1,2].

On the other hand, it was reported that physical properties of water-swollen wood are affected by drying and/or quenching histories $[3,4]$. In these reports, elastic modulus and strength were reduced, and fluidity was increased in comparison to annealed sample of water-swollen wood. And these physical properties depended on the soaking time in water after drying and/or quenching. Thus, many physical properties of wood are affected by change of environment such as moisture and temperature. These physical property changes of wood due to drying and/or quenching histories were observed from the bending test in most cases [3, 4]. On the other hand, the lateral tensile deformation property of wood with drying and/or quenching histories is not clear.

For these reasons, lateral tensile deformation properties of water-swollen wood with drying and/or quenching histories were studied. From the results obtained, the influence of these histories on lateral tensile deformation of wood were clarified, and then it was discussed whether giving these histories was effective to increase the lateral tensile deformation of wood. 


\section{Materials and methods}

\section{Samples}

Test samples of block-shaped were taken from the outer region of the log of Hinoki (Chamaecyparis obtusa). The samples with different angles of the tensile direction to the annual rings $\left(0^{\circ}, 45^{\circ}, 90^{\circ}\right)$ were made. The average ring width of the sample was about $1.1 \mathrm{~mm}$. Cross section of the block sample was sliced by a sliding microtome, because fine roughness caused by the circular saw blade can be a starting point of the failure of the sample in the tensile test. The sample size was $0.1 \mathrm{~mm}$ thickness $(L)$, $3.2 \mathrm{~mm}$ width, and $20 \mathrm{~mm}$ length.

The samples were conditioned in the manners shown in Fig. 1. Control samples were boiled for $15 \mathrm{~min}$ and were cooled slowly to $25{ }^{\circ} \mathrm{C}$ for $24 \mathrm{~h}$, and then soaked in water at $25{ }^{\circ} \mathrm{C}$ for 1 week. The samples with quenching history were boiled for $15 \mathrm{~min}$ and were put immediately into water at $25{ }^{\circ} \mathrm{C}$. The samples with drying history were obtained as follows. First, the samples were boiled for $15 \mathrm{~min}$ and were cooled slowly to $25{ }^{\circ} \mathrm{C}$ for $24 \mathrm{~h}$. Next, the samples were dried at room temperature for 1 day and dried overnight in an oven at $105^{\circ} \mathrm{C}$. And then, dried samples were impregnated with water at $25{ }^{\circ} \mathrm{C}$ under vacuum.

\section{Measurements}

The measurements were carried out in water at $25{ }^{\circ} \mathrm{C}$ by thermo-mechanical analyzer (Seiko Instruments Co., Inc. TMA/SS6100). The measurement span was $10 \mathrm{~mm}$ and the rate of load was $1 \mathrm{~N} / \mathrm{min}$. Figure 2 shows the appearance of the samples attached to the chuck. The typical stress-strain curve and average values were obtained from 10 samples where the failure occurred around the center of the span.

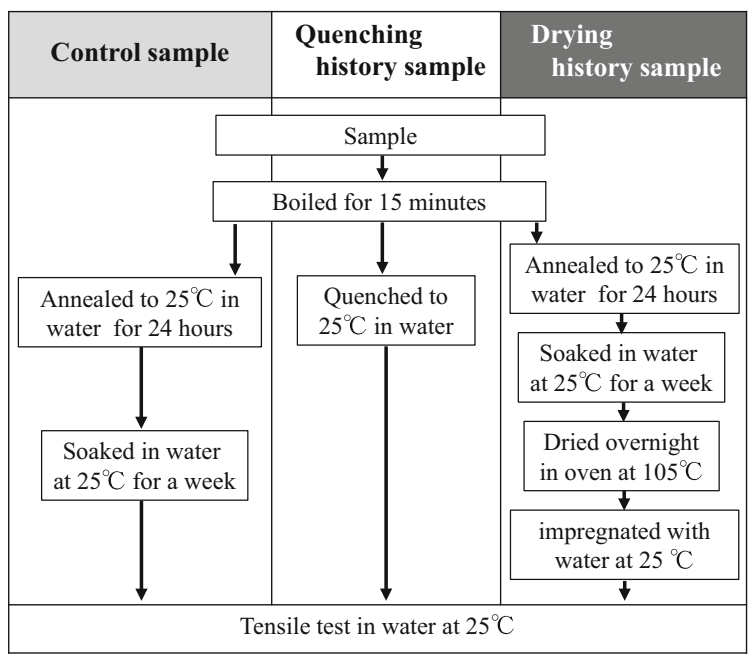

Fig. 1 The methods of conditioning

\section{Results and discussion}

\section{Stress-strain curves of wood with drying and/ or quenching histories}

Figure 3 shows typical stress-strain curves of different angle samples with different histories. In the $0^{\circ}$ angle sample, significant difference in the behavior of stress-strain curves between each sample was not found. In the $45^{\circ}$ angle sample with each history, failure strain and strength were larger than that of control sample. In all of the measurement conditions, the strain of angle $45^{\circ}$ was larger than those of angle $90^{\circ}$ and $0^{\circ}$. This result suggests as follows. It is reported the cells of the $45^{\circ}$ angle sample deformed like diamond shape during tensile test $[5,6]$. Therefore, the deformation of cell for the $45^{\circ}$ angle sample is shared larger than other angle samples. In the $90^{\circ}$ angle sample with quenching history, the gradient of stress-strain curve was smaller and strain was larger than those of control samples and samples with drying history. The gradient of the stress-strain curve of angle $90^{\circ}$ was steeper and linear than those of other angle samples. In the $90^{\circ}$ angle sample, ray tissue is arranged in the tensile direction. This should be reflected in the above result. Thus, effect of some history on the lateral tensile deformation properties was different in the each angle sample.

\section{Physical properties of wood with drying and/ or quenching histories}

To investigate the effect of drying and/or quenching histories in detail, tensile failure strain, strength and elastic modulus of each sample were obtained. Figure 4 shows a relationship between the tensile properties and tensile directions to the annual rings. The average values were obtained from 10 samples where the failure occurred around the center of the span. Samples with drying and/or quenching histories tended to have larger failure strain than those of control samples. The tendency like this was quite similar in every angle of samples.

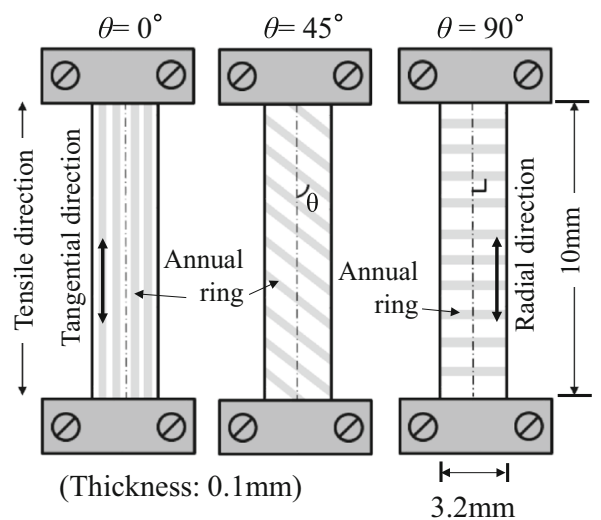

Fig. 2 The appearance of the sample attached to the chuck 


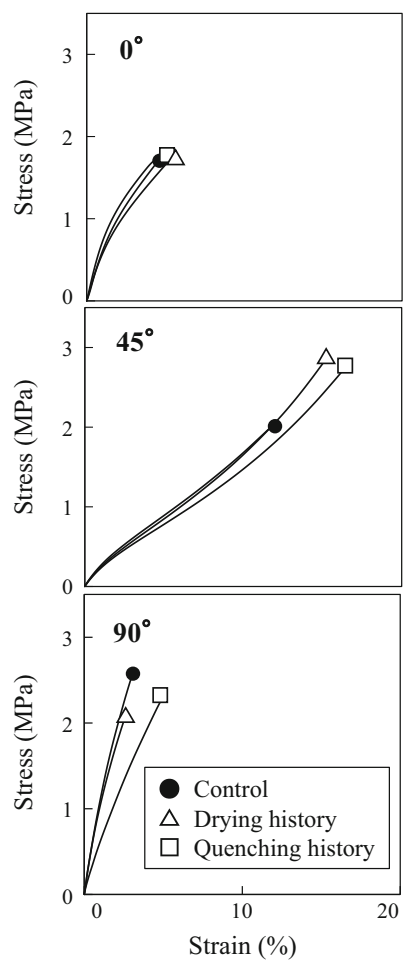

Fig. 3 The typical stress-strain curves of different angle samples with different histories. Each angle means the tensile direction to the annual rings. Symbol means each failure point

The $45^{\circ}$ angle sample with drying and/or quenching histories showed maximum value of failure strain of about $15 \%$. This result suggests that the tensile deformation of wood was increased by giving drying and/or quenching histories. The reason was considered as follows. According to the present research, the wood quenched has the value of lower modulus of elasticity (MOE) and higher fluidity than those of wood annealed which is kept at a constant temperature for a long time [3]. Kudo et al. reported that the fluidity of wood quenched from 80 to $40{ }^{\circ} \mathrm{C}$ or below was increased remarkably [4]. However, the fluidity of wood quenched from 80 to $50{ }^{\circ} \mathrm{C}$ or above did not change significantly. On the other hand, Nakano suggested the increase in relaxation behavior of wood was caused by increase in free volume in the amorphous polymer of wood constituents due to quenching treatment [7]. And, he succeeded that theoretical formula which explains the relaxation behavior of amorphous polymer could be adapted to the relaxation behavior of wood quenched. Kojiro et al. [8] studied the pore-size distribution determined by adsorption of $\mathrm{CO}_{2}$ with samples dried by outgas at various temperatures from 30 to $190{ }^{\circ} \mathrm{C}$. As a result, it was observed that the micro-spaces were decreased with elevating outgas temperature. Nakatani et al. [9] confirmed some interesting facts by measuring the adsorption of various organic liquids and $\mathrm{CO}_{2}$ for wood. That is, most of the sub nanometer order of micro-pores of wood was present in lignin. From those mentioned above, it might be considered that the value of the failure strain was increased by

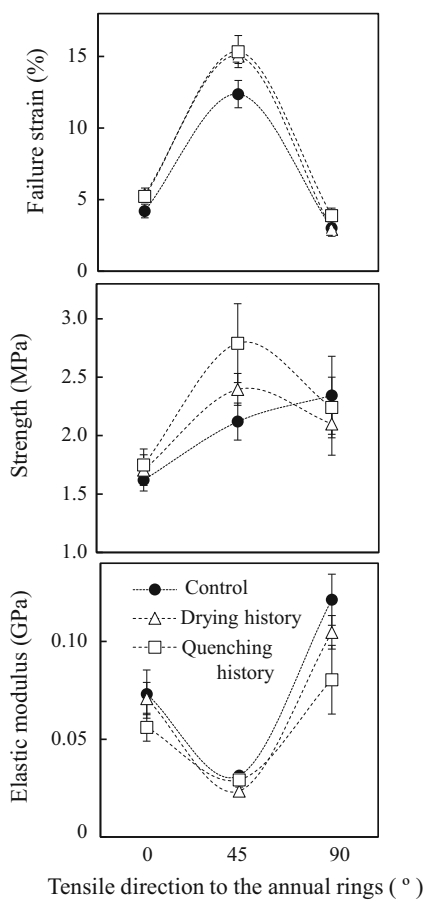

Fig. 4 Relationship between the tensile properties and tensile direction to the annual rings. Symbols mean the average value and error bars mean $95 \%$ confidence interval

increasing fluidity due to free volume mainly in lignin which was increased by giving drying and/or quenching histories.

Focusing on the strength, the values of control samples were increased in the order of $0^{\circ}, 45^{\circ}, 90^{\circ}$. The $45^{\circ}$ angle sample with drying and/or quenching histories showed maximum strength. The strength in $90^{\circ}$ angle sample was larger than that of $0^{\circ}$ angle sample. In addition, between the samples with different histories, the difference of strength was not significant in the $0^{\circ}$ and $90^{\circ}$ angle samples. However, in the $45^{\circ}$ angle sample, the strength of the samples with drying and/ or quenching histories was larger than that of control. From previous studies, bending strength of water-swollen wood was decreased by giving quenching history [3]. Therefore, the results obtained in this study were differed from that of previous study. In the $45^{\circ}$ angle sample with each history, the reason for the significant increase in strength was considered as follows. In $45^{\circ}$ angle sample, gradient of stress-strain curve is steeper with increase in strain as shown in Fig. 3. In the deforming process, cells of early wood are especially shared like diamond shape. With increasing tensile strain, the angle between the ray tissue or the late wood layer which have higher elastic modulus than that of early wood and tensile direction is decreased. Then, these tissues become bearing larger tensile stress. Therefore, it can be said that strength was also increased because the tensile strain was increased by giving drying and/or quenching histories.

Focusing on the elastic modulus, in the $45^{\circ}$ angle sample, elastic modulus was the lowest in any angle samples. In the $0^{\circ}$ 


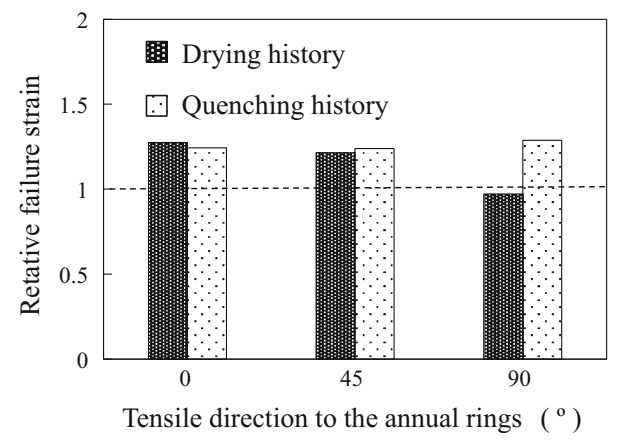

Fig. 5 Relative failure strain of different angle samples with each history. Relative failure strain means the value in sample with each history relative to that in control sample

angle sample, the elastic modulus was lower than that of $90^{\circ}$ angle sample. In samples of each angle, the elastic moduli of samples with some histories were smaller than that of control. Similar tendencies were seen in the previous studies, that is, the bending elastic modulus of water-swollen wood with some histories was smaller than those of green wood or wood annealed $[3,4,10]$. Additionally, bending elastic modulus which was decreased by giving some histories was increased with the passage of time. The reason of these results was considered as follows. When wood is given drying and/or quenching histories, molecular state of wood constituents is disturbed and microscopic strain is occurred in microstructure of wood. These microscopic strains are eliminated with the passage of time. In the eliminating process of microscopic strain, in other words, in unstable state in which the thermodynamic state of wood component transitions toward stable state, resistance of wood to external force is recovered. Therefore, it might be considered that lateral tensile elastic modulus of wood, given some histories, was also decreased as well as those of bending.

\section{Influence of drying and/or quenching histories on failure strain}

As mentioned above, the lateral tensile deformations were different in the angles of the tensile direction to the annual rings. Therefore, to consider the influence of the drying and/or quenching histories on the failure strain, it is necessary to compare the increasing value of failure strain between samples. Figure 5 shows relative failure strain of different angle samples with each history. Relative failure strain means the value in sample with each history relative to that in the control. In the $45^{\circ}$ and $0^{\circ}$ angle samples with each history, failure strain was increased about $20 \%$ in comparison to that of control samples. In $90^{\circ}$ angle sample with quenching history, failure strain was increased about $20 \%$ as well as the results of the $0^{\circ}$ and $45^{\circ}$ angle samples. On the other hand, in the sample with drying history, the failure strain did not increase. The cause of the difference in relative failure strain was considered that fine roughness which was caused during drying process contributed to tensile failure in $90^{\circ}$ angle sample. It is necessary to study in the future to clarify the cause.

From the results above, except for the $90^{\circ}$ angle sample with drying history, failure strain of the water-swollen wood at $25{ }^{\circ} \mathrm{C}$ was increased about $20 \%$ in comparison to the control sample by giving drying and/or quenching histories.

\section{Conclusions}

To clarify the influence of drying and/or quenching histories on lateral tensile deformation of wood, we studied lateral tensile deformation properties of water-swollen wood with those histories. The results obtained are as follows. In the $45^{\circ}$ angle sample with drying history, the failure strain was about $15 \%$. The value was about 3-4 times as compared to the results in the $0^{\circ}$ and $90^{\circ}$ angle samples. Further, except for the $90^{\circ}$ angle sample with drying history, failure strain was increased about $20 \%$ by giving drying and/or quenching histories. These results show that giving drying and/or quenching histories is the effective method for wood to increase the tensile deformation of the wood even in the waterswollen condition at $25^{\circ} \mathrm{C}$ because of some unstable states caused by these histories. Therefore, largely unstable states given by various kinds of histories should make it possible to increase in the lateral tensile deformation of wood.

\section{References}

1. Miyoshi Y, Kojiro K, Furuta Y (2014) Deformation properties of wood in lateral tension effect of tensile direction to the annual rings, moisture, and temperature on lateral tensile deformation of Hinoki (Chamaecyparis obtusa) (in Japanese). Mokuzai Gakkaishi 60:241-248

2. Miyoshi Y, Kojiro K, Furuta Y (2015) Effect of anatomy and thermal-softening properties on lateral tensile deformation properties of various wood species (in Japanese). J Soc Mat Sci Jpn 64:356-361

3. Iida I, Ooi K, Asada T, Wang Y, Furuta Y, Ishimaru Y (2006) The effects of quenching on the mechanical properties of wet wood (in Japanese). Mokuzai Gakkaishi 52:93-99

4. Kudo M, Iida I, Ishimaru Y, Furuta Y (2003) The effects of quenching on the mechanical properties of wet wood (in Japanese). Mokuzai Gakkaishi 49:253-259

5. Fujita S (1972) Studies on drying check VIII: deformation of structural layer during transverse tensile test (in Japanese). Mokuzai Gakkaishi 18:427-433

6. Kanaya N, Yamada T (1967) Wood by transverse tensile tests (in Japanese). Wood Res Bull Wood Res Inst Kyoto Univ 41:47-62

7. Nakano T (2005) Effects of quenching on relaxation properties of wet wood. J Wood Sci 51:112-117

8. Kojiro K, Furuta Y, Ishimaru Y (2008) Influence of heating and drying history on micropores in dry wood. J Wood Sci 54:202-207

9. Nakatani T, Ishimaru Y, Iida I, Furuta Y (2006) Absorption of some organic liquids onto the main constituents of wood (in Japanese). Mokuzai Gakkaishi 52:285-292

10. Furuta Y, Norimoto M, Yano H (1998) Thermal-softening properties of wood of water-swollen wood (in Japanese). Mokuzai Gakkaishi 44:82-88 